\title{
Alcohol consumption and risk of subarachnoid hemorrhage: A meta-analysis of 14 observational studies
}

\author{
XIYANG YAO $^{1 *}$, KAI ZHANG $^{1 *}$, JIEYONG BIAN $^{2}$ and GANG CHEN ${ }^{1}$ \\ ${ }^{1}$ Department of Neurosurgery and Brain and Nerve Research Laboratory, \\ The First Affiliated Hospital of Soochow University, Suzhou, Jiangsu 215006; \\ ${ }^{2}$ Department of Neurosurgery, Suzhou Xiangcheng People's Hospital, Suzhou, Jiangsu 215131, P.R. China
}

Received April 14,2016; Accepted August 3, 2016

DOI: $10.3892 /$ br.2016.743

\begin{abstract}
The association between alcohol consumption and the risk of subarachnoid hemorrhage (SAH) is inconsistent. Thus, meta- and a dose-response analyses are presented with the purpose of assessing their associations. A systematic literature search was performed using Pubmed and Embase electronic databases for pertinent observational studies. Random-effects or fixed-effect models were employed to combine the estimates of the relative risks (RRs) with corresponding 95\% confidence intervals (CIs). A dose-response pattern was conducted for further analysis. The current meta-analysis includes 14 observational studies reporting data on 483,553 individuals and 2,556 patients. The combined RRs of light alcohol consumption ( $<15 \mathrm{~g}$ /day) and moderate alcohol consumption (15-30 g/day) compared with teetotal individuals were 1.27 (95\% CI: $0.95,1.68)$ and 1.33 (95\% CI: $0.84,2.09)$, respectively, which indicated no significant association between light-to-moderate alcohol consumption and SAH. An increased risk of SAH was noted in heavy alcohol consumption (>30 g/day) when compared with no alcohol consumption, as demonstrated by a result of 1.78 (95\% CI: 1.46, 2.17). Dose-response analysis showed evidence of a linear association $(\mathrm{P}=0.0125)$ between alcohol consumption and SAH. The risk of SAH increased by $12.1 \%$ when alcohol consumption was increased by $10 \mathrm{~g} /$ day. Therefore,
\end{abstract}

Correspondence to: Dr Gang Chen, Department of Neurosurgery and Brain and Nerve Research Laboratory, The First Affiliated Hospital of Soochow University, 188 Shizi Street, Suzhou, Jiangsu 215006, P.R. China

E-mail: nju_neurosurgery@163.com

Mr. Jieyong Bian, Department of Neurosurgery, Suzhou Xiangcheng People's Hospital, 1060 Huayuan Road, Suzhou, Jiangsu 215131, P.R. China

E-mail: jeanne88@163.com

*Contributed equally

Key words: alcohol consumption, subarachnoid hemorrhage, dose-response, meta-analysis heavy alcohol consumption was found to be associated with an increased risk of SAH. Furthermore, the association between $\mathrm{SAH}$ and alcohol consumption has clinical relevance with regard to risk factor modification and the primary and secondary prevention of SAH.

\section{Introduction}

Subarachnoid hemorrhage $(\mathrm{SAH})$ is a destructive type of stroke, which contributes to $\geq 30 \%$ patients succumbing due to the original hemorrhage and rehemorrhage despite the development of novel treatment strategies (1-7). Although SAH is rare, it has a marked impact, particularly on young individuals, and poor outcomes $(2,8,9)$. Therefore, it is vital to investigate the risk factors of $\mathrm{SAH}$ and attempt to prevent these with the aim of reducing the incidence of $\mathrm{SAH}$. Alcohol consumption is common throughout the world and numerous observational studies have analyzed the role of alcoholic beverage intake and SAH, with some demonstrating alcohol as a risk factor or some presenting an unclear association (10-23).

In previous studies, alcohol intake and the risk of hemorrhagic stroke were investigated in the two meta-analyses, whereas intracerebral hemorrhage $(\mathrm{ICH})$ and $\mathrm{SAH}$ were not classified in either of the studies $(24,25)$. Furthermore, their investigative consequences primarily represented $\mathrm{ICH}$, as the incidence of ICH was double that of SAH (26). The impacts of alcohol consumption on the incidence of SAH are inconclusive and limited. Another two systematic reviews presented the association between alcohol intake and the risk of SAH; however, the alcohol consumption level was inexact and a further association was not identified through dose-response analysis (27,28). Thus, the current meta-analysis, which included a dose-response analysis, was performed based on previous observational studies with the aim of identifying the specific association between various levels of alcohol consumption and the risk of SAH.

\section{Materials and methods}

Study selection. This meta-analysis was conducted on the basis of the Preferred Reporting Items for Systematic Reviews and Meta-Analysis (PRISMA) statement issued 
in 2009 (29). A systematic literature search of the Pubmed (http://www.ncbi.nlm.nih.gov/pubmed) and Embase (http://www.embase.com) electronic databases for pertinent studies published from their inception to 20 January 2016 was performed by two authors (Mr. Xiyang Yao and Dr Gang Chen) independently. The search strategy used terms as follows: 'Subarachnoid hemorrhage' AND ('alcohol' OR 'alcoholic beverages' OR 'ethanol' OR 'wine' OR 'liquor' OR 'spirits' OR 'beer'). No language restriction was set. In addition, a manual search of the probable missing publications of interest in our previous literature search was based on the reference lists of relevant studies.

Publications included in our meta-analysis complied with the following criteria: i) A study of the association between alcohol consumption and $\mathrm{SAH}$; ii) case-control or cohort studies; iii) the effect estimate [relative risk (RR), hazard ratio (HR), odd ratio (OR)] and its corresponding 95\% confidence intervals (CIs) were supplied (or enough data to calclulate them); iv) alcohol consumption was classified by quantity; v) the most informative study remained in the current meta-analysis if two or more published reports were based on the same research population.

Data abstraction and quality assessment. The following data were collected: First author's last name, published year, country, study design, assessment of alcohol consumption, sample size, female proportion, age at baseline, follow up duration (years), effect estimate and its $95 \% \mathrm{CI}$, and matched or adjusted factors. The Newcastle-Ottawa Scale (NOS) (30) was selected to assess the quality of the included studies. The NOS is composed of three subscales as follows: Selection, comparability and outcome. Furthermore, it includes a range from 0 to 9 stars, and a study was considered to be of high quality when it obtained $\geq 7$ stars. Two authors (Mr. Xiyang Yao and Dr Gang Chen) gathered the data and evaluated the study quality separately. An additional author inspected and adjudicated the information according to the original studies.

Statistical analysis. RR with 95\% CI measured the association between alcohol consumption and SAH. As the prevalence of SAH was relatively low, ORs and HRs were directly considered to be RRs (31). Adjusted RRs were employed in the meta-analysis and the crude data was used when the study didn't provide the adjusted data. The $\mathrm{Q}$-statistic $(\mathrm{P}<0.1$ was identified as statistically significant) and $\mathrm{I}^{2}$ percentage $\left(\mathrm{I}^{2}\right.$ : $<50 \%$, low heterogeneity; $50-75 \%$, moderate heterogeneity; $>75 \%$, high heterogeneity) were used to evaluate the statistical heterogeneity between studies $(32,33)$. The random-effects model was used when heterogeneity existed between studies and a fixed model was adopted otherwise (34). Subgroup analyses were performed according to gender, study design, geographic area, matched or adjusted status and study quality. Sensitivity analyses were conducted by omitting one study each time to evaluate the influence of the single study on the remaining studies. In addition, publication bias for the association between alcohol consumption and the risk of SAH was statistically assessed by Egger test (35) and Begg's test (36). $\mathrm{P}<0.05$ was considered to indicate a statistically significant difference. When publication bias was apparent the "trim and fill' method was used to modify it (37).
One drink was defined as $12.5 \mathrm{~g}$, with $1 \mathrm{ml}$ as $0.8 \mathrm{~g}$ and $1 \mathrm{oz}$ as $28.35 \mathrm{~g}$ ethanol, and used grams of ethanol per day (g/day) as a standard measurement of alcohol consumption (38). The midpoint of each classification was taken as the quantity of alcohol consumption per day. When referring to the open-ended upper dose classification, it was counted as 1.2 times that of the lower bound for analyses (39). Non-drinkers were regarded as the reference category. Alcohol consumption was placed in three categories as follows: Light, $<15 \mathrm{~g} /$ day; moderate, $15-30 \mathrm{~g} /$ day; and heavy, $>30 \mathrm{~g} /$ day (25). When more than one category fell into one alcohol consumption level in certain studies, the RRs within a single category were combined for each study after which all studies were pooled (24). A dose-response analysis by generalized least squares regression models (40) was performed for further analysis and alcohol consumption (g/day) was considered as the explanatory variable. The potential curve linear correlation with alcohol consumption and SAH was evaluated using restricted cubic splines with three knots at percentiles 25,50 and $75 \%$ of the distribution (41). The null hypothesis, where the coefficient of the second spline was equal to 0 , was used to assess linearity or non-linearity according to a P-value (42). RRs with $95 \%$ CIs, distribution of cases and controls or person-years for at least three quantitative types of classifications have to be provided in initial studies. STATA 12.0 (StataCorp LP, College Station, TX, USA) was used to perform all statistical analyses.

\section{Results}

Literature search. Fig. 1 demonstrates the search flow. In total, 1,536 search records were yielded from the PubMed and Embase databases. There were 246 duplicates that were omitted, and 1,251 records were further removed after scanning the titles and abstracts, as these did not meet the inclusion criteria. The remaining 39 records were selected for full-text evaluation and 26 studies were excluded due to the following: Three studies were excluded because they were reviews (43-45). Two studies were excluded as they only investigated alcohol consumption within $24 \mathrm{~h}$ and one week before SAH, which was not representative of habitual alcohol consumption (46,47). Ten studies (48-57) that lacked sufficient data calculating RR estimates, and eight studies (58-65) where alcohol consumption had not been quantified were excluded. The remaining three studies reported on the same population (66-68). Furthermore, only one additional study of interest was identified during the manual search, which was then included (12). In total, 14 studies (10-23) were included in the current meta-analysis of which nine were cohort studies and five were case-control studies.

Study characteristics. The published period of the studies was from 1986 to 2013. Among the 14 studies, five were from the USA $(10,11,14,20,22)$, one was from Britain (19), one was from Finland (18) and seven were from Japan (12,13,15-17,21,23). A total of 480,014 individuals were reported in the cohort studies and $35.2 \%$ were male. The follow-up period of the cohorts ranged from 3.8 to 17.9 years and the number of participants ranged from 2,890 to 128,934 in every cohort study. In addition, there were 1,182 cases and 2,357 controls from the five case-control studies. Seven of the studies achieved a rating of $>6$ stars and were, therefore, considered to be high quality. 
Table I. Key characteristics of the included studies.

\begin{tabular}{|c|c|c|c|c|c|c|c|c|}
\hline $\begin{array}{l}\text { Author, } \\
\text { year (Refs.) }\end{array}$ & Country & Subjects, $\mathrm{n}$ & Gender & Cases, $\mathrm{n}$ & $\begin{array}{l}\text { Years of duration } \\
\text { or study period }\end{array}$ & $\begin{array}{c}\text { Exposure } \\
\text { assessment }\end{array}$ & $\begin{array}{c}\text { Adjusted or } \\
\text { matched variables }\end{array}$ & $\begin{array}{l}\text { NOS } \\
\text { score }\end{array}$ \\
\hline \multicolumn{9}{|l|}{ Cohort studies } \\
\hline Donahue, 1986 (10) & USA & 8006 & M & 32 & 12 & IPI & $\mathrm{a}, \mathrm{b}, \mathrm{f}, \mathrm{g}, \mathrm{i}, \mathrm{j}, \mathrm{k}$ & 6 \\
\hline Stampfer, 1988 (11) & USA & 87526 & $\mathrm{~F}$ & 28 & 3.8 & SAQ & $\mathrm{a}$ & 5 \\
\hline Iso, 1995 (12) & Japan & 2890 & M & 18 & 10.5 & IPI & $\mathrm{a}$ & 6 \\
\hline Sankai, 2000 (13) & Japan & 12372 & $\mathrm{M}+\mathrm{F}$ & 71 & 9.4 & IPI & $a, b, d, f-i$ & 8 \\
\hline Klatsky, 2002 (14) & USA & 128934 & $\mathrm{M}+\mathrm{F}$ & 133 & 7 & SAQ & $\mathrm{a}-\mathrm{d}, \mathrm{g}, \mathrm{s}$ & 7 \\
\hline Yamada, 2003 (15) & Japan & 109293 & $\mathrm{M}+\mathrm{F}$ & 244 & 9.9 & SAQ & $\mathrm{a}$ & 7 \\
\hline Iso, 2004 (16) & Japan & 19544 & M & 73 & 11 & SAQ & None & 7 \\
\hline Ikehara, 2013 (17) & Japan & 47100 & $\mathrm{~F}$ & 338 & 16.7 & SAQ & $\mathrm{a}, \mathrm{d}-\mathrm{f}-\mathrm{i}, \mathrm{m}-\mathrm{o}$ & 7 \\
\hline Korja, 2013 (18) & Finland & 64349 & $\mathrm{M}+\mathrm{F}$ & 437 & Median 17.9 & SAQ & $a, b$ & 6 \\
\hline \multicolumn{9}{|l|}{ Case-control studies } \\
\hline Gill, 1991 (19) & Britain & 766 & $\mathrm{M}+\mathrm{F}$ & 193 & NR & SAQ & $a-d, f, p-q, r$ & 6 \\
\hline Longstreth, 1992 (20) & USA & 447 & $\mathrm{M}+\mathrm{F}$ & 149 & 1987-1989 & IPI & $a, b$ & 7 \\
\hline Kubota, 2001 (21) & Japan & 254 & $\mathrm{M}+\mathrm{F}$ & 127 & NR & SAQ & $a, b$ & 7 \\
\hline Qureshi, 2001 (22) & USA & 1292 & $\mathrm{M}+\mathrm{F}$ & 323 & 1990-1997 & MR & $a-c$ & 4 \\
\hline Ohkuma, 2003 (23) & Japan & 780 & $\mathrm{M}+\mathrm{F}$ & 390 & 2000-2001 & SAQ & None & 5 \\
\hline
\end{tabular}

Adjusted or matched variables were: (a) Age, (b) gender, (c) race, (d) cigarette smoking, (e) area, (f) hypertension, (g) BMI, (h) DM, (i) cholesterol, (j) uric acid and glucose concentrations, (k) hematocrit, (l) menopausal status, (m) mental stress, (n) facial redness after alcohol consumption, (o) sports at leisure time, (p) socioeconomic class, (q) treatment of hypertension, (r) medication, (s) education. M, male; F, female; NR, not reported; IPI, in-person interview; SAQ, self-administered questionnaire; MR, medical records; BMI, body mass index; DM, diabetes mellitus.

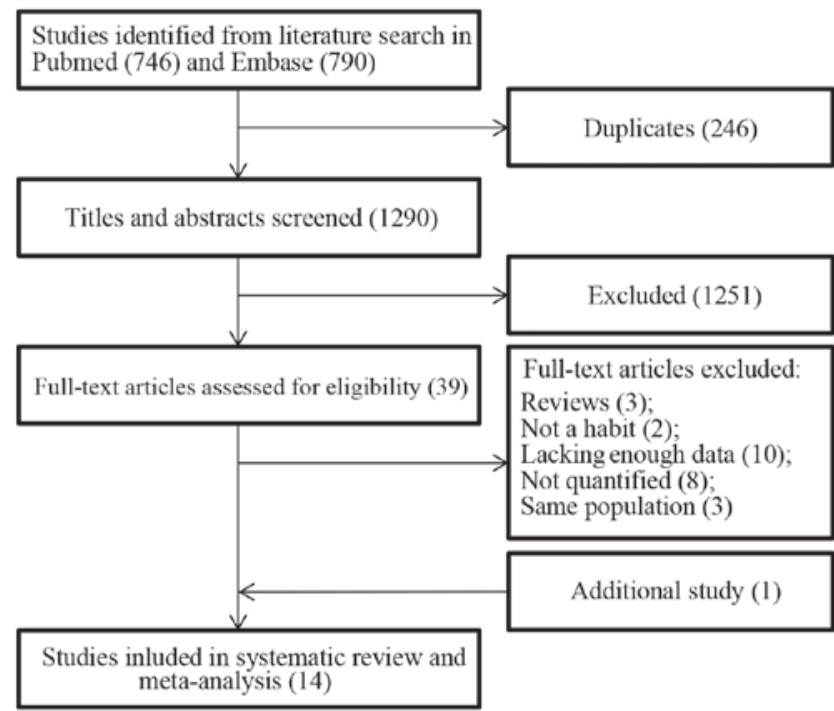

Figure 1. Flowchart of the search process.

Whereas, the remaining seven studies were considered to be low quality as a result of the star rating. Detailed characteristics are presented in Table I.

Alcohol consumption and risk of SAH. Figs. 2-4 demonstrate the outcomes from the random-effects model (light and moderate alcohol consumption) or fixed-effect model (heavy alcohol consumption) of pooled RRs for SAH. The combined RR of light alcohol consumption $(<15 \mathrm{~g} /$ day) and moderate alcohol consumption (15-30 g/day) compared with no alcohol consumption were $1.27\left(95 \% \mathrm{CI}: 0.95,1.68 ; \mathrm{I}^{2}=61.9 \% ; \mathrm{P}=0.005\right.$ for heterogeneity) and 1.33 (95\% CI: 0.84, 2.09; $\mathrm{I}^{2}=59.6 \%$; $\mathrm{P}=0.022$ for heterogeneity), respectively, which indicated no significant association between light or moderate alcohol consumption and SAH. Furthermore, the summary RR showed an increased risk of SAH when heavy alcohol consumption ( $>30 \mathrm{~g} /$ day) was compared with no alcohol consumption, with a pooled result of 1.78 (95\% CI: $1.46,2.17 ; \mathrm{I}^{2}=23.0 \% ; \mathrm{P}=0.218$ for heterogeneity).

Stratified analyses. To minimize heterogeneity, stratified analyses were conducted between the included studies. The subgroups were generated in terms of pivotal study characteristics: Study design, gender, geographic area, type of SAH, study quality and adjustment status (smoking and blood pressure). The intact stratified results are presented in Table II.

For light alcohol consumption, total RRs of light alcohol consumption were not identified to be associated with the risk of SAH and had a moderate heterogeneity. However, if the study design was cohort, light alcohol consumption was observed to have an increased association with the risk of SAH and low heterogeneity, with RR of 1.53 (95\% CI: 1.16, $2.02 ; \mathrm{I}^{2}=35.7 \% ; \mathrm{P}=0.156$ for heterogeneity). Furthermore, the pooled RR of 1.46 (95\% CI: $1.11,1.93 ; \mathrm{I}^{2}=0 \% ; \mathrm{P}=0.468$ for 


\begin{tabular}{|c|c|}
\hline $\begin{array}{l}\text { Study } \\
\text { ID }\end{array}$ & $\begin{array}{l}\text { Random-effects } \% \\
\text { RR }(95 \% \mathrm{CI}) \quad \text { Weight }\end{array}$ \\
\hline Donahue 1986 & $\Rightarrow 2.80(0.90,8.60) 4.75$ \\
\hline Stampfer 1988 & $3.54(1.67,7.47) 8.19$ \\
\hline Gill 1991 & $0.67(0.40,1.10) 11.87$ \\
\hline Longstreth 1992 & $0.70(0.40,1.10) 11.87$ \\
\hline Iso 1995 & $0.32(0.02,6.60) 0.91$ \\
\hline Qureshi 2001 & $1.40(0.90,2.10) 13.38$ \\
\hline Yamada 2003 & $1.04(0.62,1.76) 11.59$ \\
\hline Iso 2004 & $1.43(0.62,3.31) 7.17$ \\
\hline Ikehara 2013 & $1.42(0.94,2.13) 13.65$ \\
\hline Korja 2013 & $1.45(1.13,1.86) 16.61$ \\
\hline Overall $(\mathrm{I}-\mathrm{squared}=61.9 \%, \mathrm{p}=0.005)$ & $1.27(0.95,1.68) 100.00$ \\
\hline
\end{tabular}

Figure 2. Forest plot of the association between light alcohol consumption and the risk of subarachnoid hemorrhage.

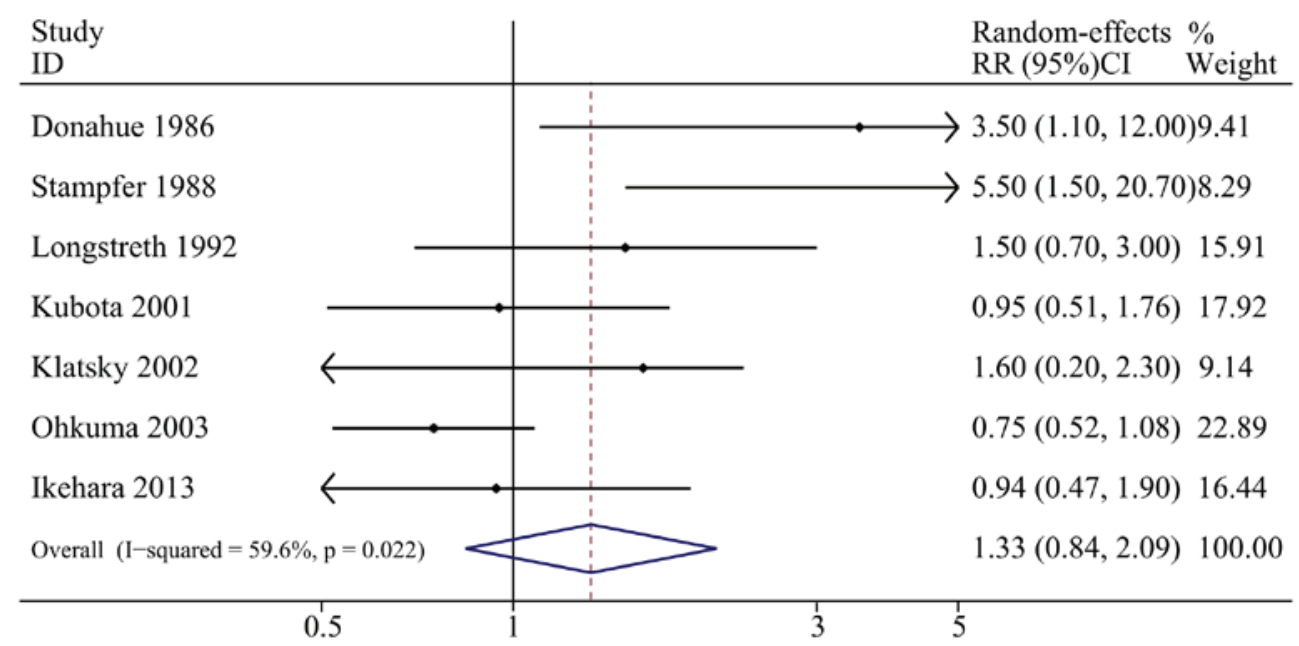

Figure 3. Forest plot of the association between moderate alcohol consumption and the risk of subarachnoid hemorrhage.

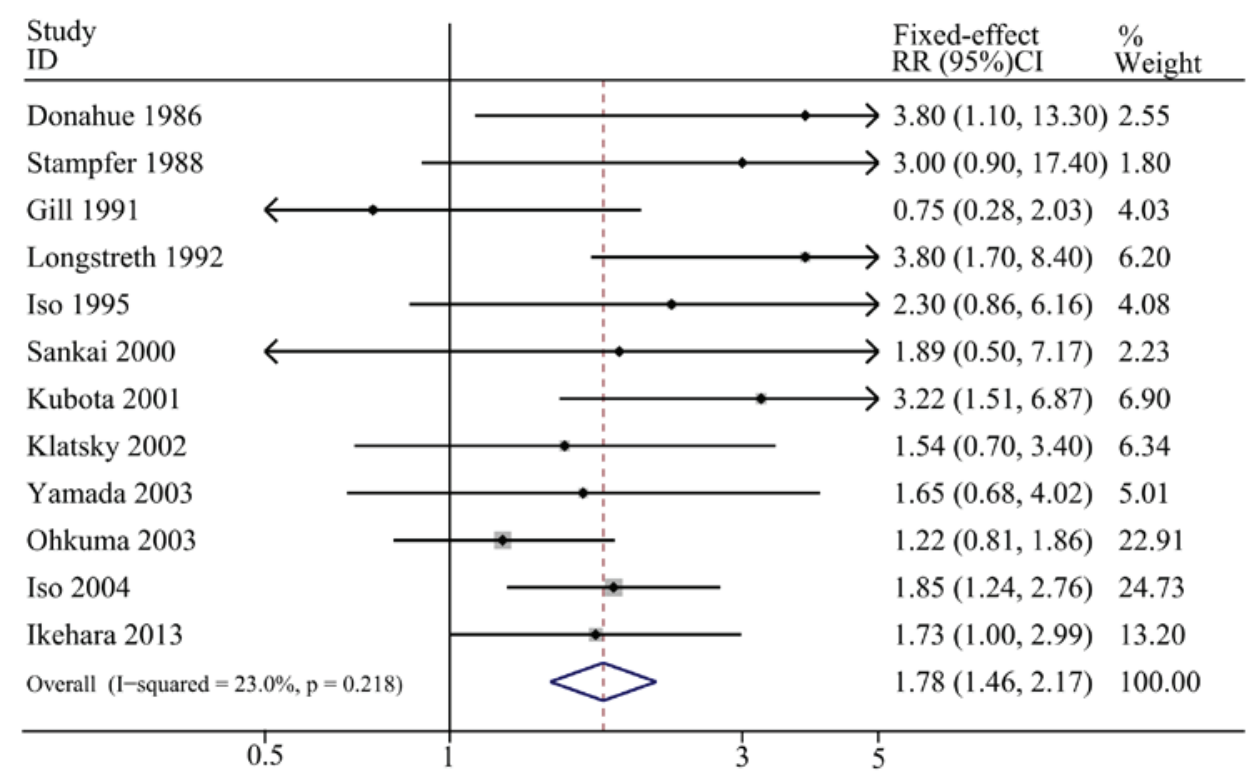

Figure 4. Forest plot of the association between heavy alcohol consumption and the risk of subarachnoid hemorrhage. 
Table II. Summary RRs for alcohol consumption and SAH.

\begin{tabular}{|c|c|c|c|c|c|c|}
\hline & \multicolumn{2}{|c|}{$\begin{array}{l}\text { Low alcohol } \\
\text { consumption }\end{array}$} & \multicolumn{2}{|c|}{$\begin{array}{l}\text { Moderate alcohol } \\
\text { consumption }\end{array}$} & \multicolumn{2}{|c|}{$\begin{array}{c}\text { Heavy low } \\
\text { alcohol consumption }\end{array}$} \\
\hline & RR (95\% CI) & P-value ${ }^{a}$ & $\mathrm{RR}(95 \% \mathrm{CI})$ & P-value & $\mathrm{RR}(95 \% \mathrm{CI})$ & P-value \\
\hline Total outcomes & $1.27(0.95,1.68)$ & 0.10 & $1.33(0.84,2.09)$ & 0.23 & $1.78(1.46,2.17)$ & $<0.01$ \\
\hline \multicolumn{7}{|l|}{ Study design } \\
\hline Cohort & $1.53(1.16,2.02)$ & $<0.01$ & $2.08(0.90,4.81)$ & 0.09 & $1.88(1.46,2.43)$ & $<0.01$ \\
\hline Case-control & $0.88(0.54,1.68)$ & 0.63 & $1.33(0.84,2.09)$ & 0.68 & $1.64(1.20,2.24)$ & $<0.01$ \\
\hline \multicolumn{7}{|l|}{ Gender } \\
\hline Men & $1.46(1.11,1.93)$ & $<0.01$ & $3.5(1.5,20.7)$ & 0.04 & $1.77(1.36,2.30)$ & $<0.01$ \\
\hline Women & $1.33(0.82,2.18)$ & 0.25 & $2.41(0.66,8.78)$ & 0.18 & $1.27(0.90,1.79)$ & 0.18 \\
\hline \multicolumn{7}{|l|}{ Geographic area } \\
\hline North America & $1.63(0.81,3.27)$ & 0.17 & $2.16(1.29,3.59)$ & $<0.01$ & $2.64(1.63,4.28)$ & $<0.01$ \\
\hline Asia & $1.26(0.94,1.70)$ & 0.13 & $0.82(0.62,1.09)$ & 0.17 & $1.71(1.37,2.14)$ & $<0.01$ \\
\hline Europe & $1.02(0.48,2.16)$ & 0.96 & I & 1 & $0.75(0.28,2.02)$ & 0.57 \\
\hline \multicolumn{7}{|l|}{ Type of SAH } \\
\hline Total SAH & $1.27(0.95,1.68)$ & 0.10 & $1.61(1.07,2.44)$ & 0.02 & $1.90(1.50,2.41)$ & $<0.01$ \\
\hline aSAH & - & - & $0.80(0.58,1.09)$ & 0.16 & $1.53(1.06,2.20)$ & 0.02 \\
\hline \multicolumn{7}{|l|}{ Study quality } \\
\hline Low & $1.49(0.75,2.98)$ & 0.26 & $2.19(0.54,8.85)$ & 0.27 & $1.41(1.01,1.97)$ & 0.04 \\
\hline High & $1.20(0.91,1.57)$ & 0.20 & $1.12(0.77,1.63)$ & 0.55 & $2.02(1.58,2.59)$ & 0.02 \\
\hline \multicolumn{7}{|c|}{ Adjusted smoking } \\
\hline Yes & $1.23(0.62,2.45)$ & 0.56 & $1.54(0.71,3.36)$ & 0.27 & $1.62(1.09,2.39)$ & 0.04 \\
\hline No & $1.31(0.94,1.83)$ & 0.12 & $1.25(0.68,2.30)$ & 0.47 & $2.02(1.45,2.81)$ & $<0.01$ \\
\hline \multicolumn{7}{|c|}{ Adjusted blood pressure } \\
\hline Yes & $1.23(0.62,2.45)$ & 0.57 & $1.65(0.46,5.92)$ & 0.44 & $1.64(0.94,2.87)$ & 0.01 \\
\hline No & $1.31(0.94,1.83)$ & 0.12 & $1.27(0.74,2.18)$ & 0.38 & $1.93(1.44,2.58)$ & $<0.01$ \\
\hline
\end{tabular}

${ }^{a} \mathrm{P}<0.05$ was considered to indicate a statistically significant difference. RR, relative risk; CI, confidence interval; $\mathrm{SAH}$, subarachnoid hemorrhage; aSAH, aneurysmal subarachnoid hemorrhage.

heterogeneity) was statistically significant and there was no evidence of heterogeneity with regard to men and light alcohol consumption. No further statistically significant data was found in the geographic area, types of SAH, adjustment for smoking, adjustment for blood pressure and study quality.

For moderate alcohol consumption, no statistical significance was identified with the overall RRs of moderate alcohol consumption compared with the risk of $\mathrm{SAH}$, and moderate heterogeneity was indicated. Notably, low heterogeneity was observed and an increased risk between moderate alcohol consumption and SAH was identified when the geographic area was North America and the type of SAH was total SAH. Furthermore, only one study mentioned the data regarding association with moderate alcohol consumption and the risk of SAH in a male population. No statistically significant information was found according to the results of the groups, such as study design, study quality and adjustments.

For heavy alcohol consumption, the RRs of women and adjustment for blood pressure along with heavy alcohol consumption did not show statistical significance with the risk of $\mathrm{SAH}$, while other items indicated a statistically significant increased risk (Table II).
Sensitivity analyses and publication bias. The outcomes of sensitivity analyses were not identified to be significantly varied (data not shown). The Egger test $(\mathrm{P}=0.906)$ and Begg's test $(\mathrm{P}=0.719)$ indicated no evidence of publication bias for the association with light alcohol consumption and the risk of SAH. For heavy alcohol consumption, similar results were observed with the Egger test $(\mathrm{P}=0.235)$ and Begg's test $(\mathrm{P}=0.493)$. However, potential evidence of publication bias was found for SAH risk with moderate alcohol consumption according to the Egger test $(\mathrm{P}=0.004)$ and Begg's test $(\mathrm{P}=0.011)$. The adjusted result from the 'trim and fill' method for publication bias was 0.94 (95\% CI: 0.57, 1.53), which did not change the former conclusions for SAH risk and moderate alcohol consumption. Fig. 5 demonstrates the funnel plot after applying the 'trim and fill' method.

Dose-response association. Seven studies were included in the dose-response analysis of alcohol consumption with SAH risk $(10,11,14,16,17,19,20)$. A linear increase in SAH with increasing alcohol consumption $(\mathrm{P}=0.013)$ was observed after accessing dose-response patterns for alcohol consumption (g/day) for alcohol consumers vs. teetotal individuals (Fig. 6). 
Filled funnel plot with pseudo $95 \%$ confidence limits

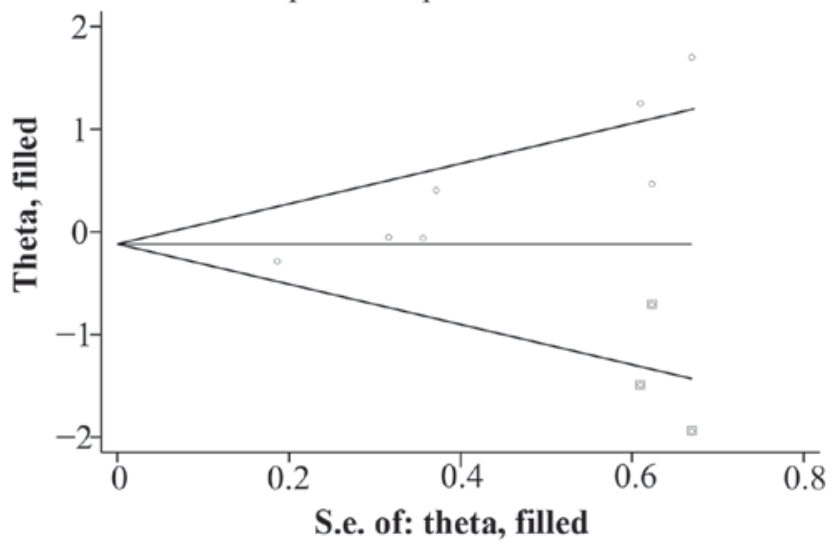

Figure 5. Presence of three potentially unreported studies were estimated using the 'trim and fill' method. S.e., standard error.

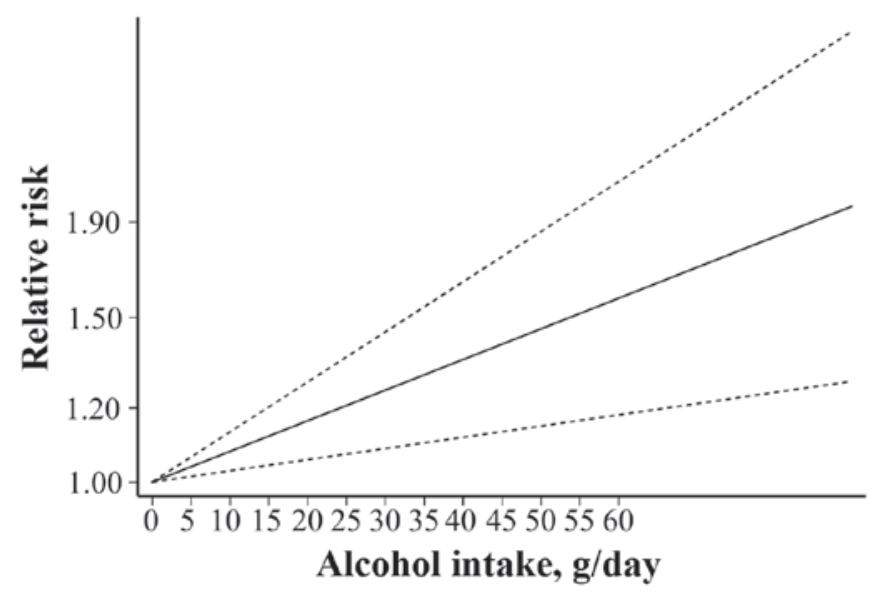

Figure 6. Dose-response correlation between subarachnoid hemorrhage risk and alcohol consumption. The solid line signifies the estimated relative risks and the dashed lines signify the $95 \%$ confidence intervals.

Furthermore, the risk increased by $12.1 \%$ for each additional $10 \mathrm{~g} /$ day of alcohol consumption.

\section{Discussion}

In the past several decades, the role of alcohol intake in the development of SAH has been increasingly recognized. Teunissen et al (27) conducted a systematic review about the risk factors for $\mathrm{SAH}$, which five studies referring to alcohol intake and the risk of SAH. Alcohol abuse was identified to be a significant risk factor for $\mathrm{SAH}$, with the results of drinking $\geq 21.4 \mathrm{~g} /$ day alcohol being $\mathrm{RR}=4.7$ (95\% CI: 2.1 , $10.5)$ according to two longitudinal studies, and odds ratio $(\mathrm{OR})=1.5(95 \%$ CI: 1.1, 1.9) according to three case control studies. Subsequently, an updated systematic review of epidemiological studies was conducted by the same group, which demonstrated no different conclusions with the inclusion of extra studies (28). The current meta-analysis was based on observational studies that had quantified alcohol consumption with the aim of identifying probable correlations between alcohol consumption and the risks of SAH. The analysis included 483,553 individuals and 2,556 patients from nine cohort and five case-control studies. The results indicated that there was no correlation between light or moderate alcohol consumption and the risk of SAH, while an increased risk of SAH was found to be associated with heavy alcohol consumption. The dose-response analysis evidenced a distinct linear association between alcohol consumption and $\mathrm{SAH}$, which was consistent with the findings of Leppala et al (69). In addition, the dose-response analysis indicated an increased risk of $12.1 \%$ for every increase of $10 \mathrm{~g} /$ day alcohol when comparing drinkers to teetotal individuals.

The current findings confirmed the results from previous systematic reviews $(27,28)$. Furthermore, the accuracy of the risk estimates was augmented with the accumulative data and stratified analyses were executed to evaluate the origin of heterogeneity (70), thereby advancing the clinical association of the present findings. Subgroup analysis indicated that light alcohol consumption was associated with an increase in SAH risk in cohort studies and men. Smoking was confirmed to be an independent risk factor for SAH $(20,21,52,71,72)$ and men smoked more than women, which may be the explanation for the association between light alcohol consumption and the increased risk of SAH in men. Moderate alcohol consumption was associated with an increased risk of SAH in North American individuals; however, the explanation of this finding was unclear and requires additional investigation to be confirmed. Hypertension (73), reducing platelet aggregation (74) and enhancing fibrinolysis from endothelial cells (75) may be the reasons for the association between an increased risk of SAH and heavy alcohol consumption; although heavy alcohol consumption was not significantly associated with SAH in women. The potential reasons are as follows: i) Heavy drinkers were likely to be inclined to take part in the surveys as participants and less willing to complete repeat questionnaires in detail (11); ii) all volunteers in the study by Stampfer et al (11) were female nurses who may have had knowledge of the negative outcomes of drinking excessively, and therefore avoided heavy drinking (11); and iii) small population number $(13,19)$. Notably, although hypertension has been consistently considered as the strongest predictor of SAH in previous studies (76-80), no correlation was found between heavy alcohol consumption and SAH risk in individuals from the included studies, which adjusted for blood pressure $(10,13,17,19)$. However, the association between alcohol and stroke diminished markedly when adjusting for varying hypertension (3).

A notable strength of the present study is that it contains a broader individual population and has a longer follow-up when compared with previous studies. However, when interpreting the outcomes of the current meta-analysis, certain limitations should also be considered. First, the impact of potential confounding factors is a well-known issue resulting from the observational design of all of the included studies. In consideration of an osculating association between alcohol consumption and demographic, family history and lifestyle factors, the residual confounding factor should be categorized distinctly between these variables in future research. Second, information, select and recall bias usually lead to overestimating and underestimating the real associations in the observational studies. Furthermore, evidence of publication bias existed when pooling the results of correlation 
with moderate alcohol consumption and the risk of SAH, although the conclusion remained unchanged following the 'trim and fill' method. Third, the strength of the correlation may have been weakened by misclassification bias. As the alcohol consumption assessment was based on self-reports and self-administered questionnaires, misclassification bias was inevitable. Finally, stratified analyses to examine the influence of different types of alcohol consumption on these correlations were conducted on account of the limited number of studies.

The present findings reveal various implications that are significant to public health. Individuals who reduce their alcohol consumption may also reduce their risk of SAH. Therefore, subjects who are alcohol drinkers should be encouraged to modify their habits to diminish the possibility of heavy alcohol consumption. Although small quantities of alcohol consumption are thought to reduce the risk of ischemic stroke $(24,25)$, alcohol indeed promotes certain types of cancer, such as colorectal and gastric cancer $(81,82)$ and, according to the present meta-analysis, increases the risk of SAH.

In conclusion, heavy alcohol consumption ( $>30 \mathrm{~g} /$ day $)$ is associated with increased risk of SAH. The association between alcohol consumption and SAH has clinical implications for primary and secondary prevention of SAH. The implications of the findings require careful evaluation, as any suggestion regarding alcohol consumption must be tailored to the risks of each individual patient.

\section{Acknowledgements}

The present study was supported by Suzhou Key Medical Center (grant no. Szzx201501), grants from the National Natural Science Foundation of China (grant nos. 81571115, 81422013 and 81471196), the Scientific Department of Jiangsu Province (grant no. BL2014045), Suzhou Government (grant nos. LCZX201301, SZS201413 and SYS201332) and A Project Funded by the Priority Academic Program Development of Jiangsu Higher Education Institutions.

\section{References}

1. Hanel RA, Xavier AR, Mohammad Y, Kirmani JF, Yahia AM and Qureshi AI: Outcome following intracerebral hemorrhage and subarachnoid hemorrhage. Neurol Res 24 (Suppl 1): S58-S62, 2002.

2. Johnston SC, Selvin S and Gress DR: The burden, trends, and demographics of mortality from subarachnoid hemorrhage. Neurology 50: 1413-1418, 1998.

3. Hasegawa $Y$, Suzuki $H$ and Uekawa K, Kawano $T$ and Kim-Mitsuyama S: Characteristics of cerebrovascular injury in the hyperacute phase after induced severe subarachnoid hemorrhage. Transl Stroke Res 6: 458-466, 2015.

4. Marbacher S, Nevzati E, Croci D, Erhardt S, Muroi C, Jakob SM and Fandino J: The rabbit shunt model of subarachnoid haemorrhage. Transl Stroke Res 5: 669-680, 2014.

5. Pluta RM, Bacher J, Skopets B and Hoffmann V: A non-human primate model of aneurismal subarachnoid hemorrhage (SAH). Transl Stroke Res 5: 681-691, 2014.

6. Turan N, Heider RA, Zaharieva D, Ahmad FU, Barrow DL and Pradilla G: Sex differences in the formation of intracranial aneurysms and incidence and outcome of subarachnoid hemorrhage: Review of experimental and human studies. Transl Stroke Res 7: 12-19, 2016.

7. Cheng C, Jiang L, Yang Y, Wu H, Huang Z and Sun X: Effect of APOE gene polymorphism on early cerebral perfusion after aneurysmal subarachnoid hemorrhage. Transl Stroke Res 6: 446-450, 2015.
8. Linn FH, Rinkel GJ, Algra A and van Gijn J: Incidence of subarachnoid hemorrhage: Role of region, year, and rate of computed tomography: A meta-analysis. Stroke 27: 625-629, 1996.

9. Etminan N: Aneurysmal subarachnoid hemorrhage-status quo and perspective. Transl Stroke Res 6: 167-170, 2015.

10. Donahue RP, Abbott RD, Reed DM and Yano K: Alcohol and hemorrhagic stroke. The honolulu heart program. JAMA 255: 2311-2314, 1986.

11. Stampfer MJ, Colditz GA, Willett WC, Speizer FE and Hennekens CH: A prospective study of moderate alcohol consumption and the risk of coronary disease and stroke in women. N Engl J Med 319: 267-273, 1988.

12. Iso H, Kitamura A, Shimamoto T, Sankai T, Naito Y, Sato S, Kiyama M, Iida M and Komachi Y: Alcohol intake and the risk of cardiovascular disease in middle-aged Japanese men. Stroke 26: 767-773, 1995.

13. Sankai T, Iso H, Shimamoto T, Kitamura A, Naito Y, Sato S, Okamura T, Imano H, Iida M and Komachi Y: Prospective study on alcohol intake and risk of subarachnoid hemorrhage among Japanese men and women. Alcohol Clin Exp Res 24: 386-389, 2000.

14. Klatsky AL, Armstrong MA,Friedman GD and Sidney S: Alcohol drinking and risk of hemorrhagic stroke. Neuroepidemiology 21: $115-122,2002$.

15. Yamada S, Koizumi A, Iso H, Wada Y, Watanabe Y, Date C, Yamamoto A, Kikuchi S, Inaba Y, Toyoshima H, et al: Risk factors for fatal subarachnoid hemorrhage: The Japan collaborative cohort study. Stroke 34: 2781-2787, 2003.

16. Iso H, Baba S, Mannami T, Sasaki S, Okada K, Konishi M and Tsugane S; JPHC Study Group: Alcohol consumption and risk of stroke among middle-aged men: The JPHC study cohort I. Stroke 35: 1124-1129, 2004

17. Ikehara S, Iso H, Yamagishi K, Kokubo Y, Saito I, Yatsuya H, Inoue M and Tsugane S; JPHC Study group: Alcohol consumption and risk of stroke and coronary heart disease among Japanese women: The Japan public health center-based prospective study. Prev Med 57: 505-510, 2013.

18. Korja M, Silventoinen K, Laatikainen T, Jousilahti P, Salomaa V, Hernesniemi J and Kaprio J: Risk factors and their combined effects on the incidence rate of subarachnoid hemorrhage-a population-based cohort study. PLoS One 8: e73760, 2013.

19. Gill JS, Shipley MJ, Tsementzis SA, Hornby RS, Gill SK, Hitchcock ER and Beevers DG: Alcohol consumption-a risk factor for hemorrhagic and non-hemorrhagic stroke. Am J Med 90: 489-497, 1991.

20. Longstreth WT Jr, Nelson LM, Koepsell TD and van Belle G: Cigarette smoking, alcohol use, and subarachnoid hemorrhage. Stroke 23: 1242-1249, 1992

21. Kubota M, Yamaura A and Ono J: Prevalence of risk factors for aneurysmal subarachnoid haemorrhage: Results of a Japanese multicentre case control study for stroke. Br J Neurosurg 15: 474-478, 2001.

22. Qureshi AI, Suri MF, Yahia AM, Suarez JI, Guterman LR, Hopkins LN and Tamargo RJ: Risk factors for subarachnoid hemorrhage. Neurosurgery 49: 607-613, 2001.

23. Ohkuma H, Tabata H, Suzuki S and Islam MS: Risk factors for aneurysmal subarachnoid hemorrhage in Aomori, Japan. Stroke 34: 96-100, 2003.

24. Reynolds K, Lewis B, Nolen JD, Kinney GL, Sathya B and He J: Alcohol consumption and risk of stroke: A meta-analysis. JAMA 289: 579-588, 2003.

25. Zhang C, Qin YY, Chen Q, Jiang H, Chen XZ, Xu CL, Mao PJ, He J and Zhou YH: Alcohol intake and risk of stroke: A dose-response meta-analysis of prospective studies. Int $\mathbf{J}$ Cardiol 174: 669-677, 2014.

26. Broderick JP, Brott T, Tomsick T, Miller R and Huster G: Intracerebral hemorrhage more than twice as common as subarachnoid hemorrhage. J Neurosurg 78: 188-191, 1993.

27. Teunissen LL, Rinkel GJ, Algra A and van Gijn J: Risk factors for subarachnoid hemorrhage: A systematic review. Stroke 27: 544-549, 1996.

28. Feigin VL, Rinkel GJ, Lawes CM, Algra A, Bennett DA, van Gijn J and Anderson CS: Risk factors for subarachnoid hemorrhage: An updated systematic review of epidemiological studies. Stroke 36: 2773-2780, 2005.

29. Moher D, Liberati A, Tetzlaff J and Altman DG; PRISMA Group: Preferred reporting items for systematic reviews and meta-analyses: The PRISMA statement. PLoS Med 6: e1000097, 2009. 
30. Wells GA, Shea B, O'Connell D, Peterson J, Welch V and Tugwell P: The Newcastle-Ottawa Scale (NOS) for Assessing the Quality of Nonrandomised Studies in Meta-Analyses. Available online: http://www.ohri.ca/programs/clinical_epidemiology/oxford.htm. Accessed February 25, 2016.

31. Greenland S: Quantitative methods in the review of epidemiologic literature. Epidemiol Rev 9: 1-30, 1987.

32. Higgins JP and Thompson SG: Quantifying heterogeneity in a meta-analysis. Stat Med 21: 1539-1558, 2002.

33. Higgins JP, Thompson SG, Deeks JJ and Altman DG: Measuring inconsistency in meta-analyses. BMJ 327: 557-560, 2003.

34. Ali-Hassan-Sayegh S, Mirhosseini SJ, Tahernejad M, Mahdavi P, Haddad F, Shahidzadeh A, Lotfaliani MR, Sedaghat-Hamedani F, Kayvanpour E, Weymann A, et al: Administration of erythropoietin in patients with myocardial infarction: Does it make sense? An updated and comprehensive meta-analysis and systematic review. Cardiovasc Revasc Med 16: 179-189, 2015.

35. Egger M, Davey Smith G, Schneider M and Minder C: Bias in meta-analysis detected by a simple, graphical test. BMJ 315: 629-634, 1997

36. Begg CB and Mazumdar M: Operating characteristics of a rank correlation test for publication bias. Biometrics 50: 1088-1101, 1994.

37. Duval S and Tweedie R: Trim and fill: A simple funnel-plot-based method of testing and adjusting for publication bias in meta-analysis. Biometrics 56: 455-463, 2000.

38. Galeone C, Malerba S, Rota M, Bagnardi V, Negri E, Scotti L, Bellocco R, Corrao G, Boffetta P, La Vecchia C and Pelucchi C: A meta-analysis of alcohol consumption and the risk of brain tumours. Ann Oncol 24: 514-523, 2013.

39. Berlin JA, Longnecker MP and Greenland S: Meta-analysis of epidemiologic dose-response data. Epidemiology 4: 218-228, 1993.

40. Greenland S and Longnecker MP: Methods for trend estimation from summarized dose-response data, with applications to meta-analysis. Am J Epidemiol 135: 1301-1309, 1992.

41. Ma Y, Zhang P, Wang F, Yang J, Liu Z and Qin H: Association between vitamin $\mathrm{D}$ and risk of colorectal cancer: A systematic review of prospective studies. J Clin Oncol 29: 3775-3782, 2011.

42. Harrell FE Jr, Lee KL and Pollock BG: Regression models in clinical studies: Determining relationships between predictors and response. J Natl Cancer Inst 80: 1198-1202, 1988.

43. Daniel S and Bereczki D: Alcohol as a risk factor for hemorrhagic stroke. Ideggyogy Sz 57: 247-256, 2004

44. Hillbom M, Saloheimo P and Juvela S: Alcohol consumption, blood pressure, and the risk of stroke. Curr Hypertens Rep 13: 208-213, 2011

45. Andreasen TH, Bartek J Jr, Andresen M, Springborg JB and Romner B: Modifiable risk factors for aneurysmal subarachnoid hemorrhage. Stroke 44: 3607-3612, 2013.

46. Juvela S, Hillbom M, Numminen H and Koskinen P: Cigarette smoking and alcohol consumption as risk factors for aneurysmal subarachnoid hemorrhage. Stroke 24: 639-646, 1993.

47. Anderson C, Ni Mhurchu C, Scott D, Bennett D, Jamrozik K and Hankey G; Australasian Cooperative Research on Subarachnoid Hemorrhage Study Group: Triggers of subarachnoid hemorrhage: Role of physical exertion, smoking, and alcohol in the Australasian cooperative research on subarachnoid hemorrhage study (ACROSS). Stroke 34: 1771-1776, 2003.

48. Acuña MY and A Cifuentes L: Aneurismal subarachnoid hemorrhage in a Chilean population, with emphasis on risk factors. BMC Res Notes 4: 464, 2011.

49. Broderick JP, Viscoli CM, Brott T, Kernan WN, Brass LM Feldmann E, Morgenstern LB, Wilterdink JL and Horwitz RI; Hemorrhagic Stroke Project Investigators: Major risk factors for aneurysmal subarachnoid hemorrhage in the young are modifiable. Stroke 34: 1375-1381, 2003

50. Jung SY, Bae HJ, Park BJ and Yoon BW; Acute Brain Bleeding Analysis Study Group: Parity and risk of hemorrhagic strokes. Neurology 74: 1424-1429, 2010.

51. Bateman BT, Olbrecht VA, Berman MF, Minehart RD, Schwamm LH and Leffert LR: Peripartum subarachnoid hemorrhage: Nationwide data and institutional experience. Anesthesiology 116: 324-333, 2012.

52. Juvela S: Prevalence of risk factors in spontaneous intracerebral hemorrhage and aneurysmal subarachnoid hemorrhage. Arch Neurol 53: 734-740, 1996.

53. Jiménez-Yepes $\mathrm{CM}$ and Londoño-Fernández JL: Risk of aneurysmal subarachnoid hemorrhage: The role of confirmed hypertension. Stroke 39: 1344-1346, 2008.
54. Hamdan A, Barnes J and Mitchell P: Subarachnoid hemorrhage and the female sex: Analysis of risk factors, aneurysm characteristics, and outcomes. J Neurosurg 121: 1367-1373, 2014.

55. Ben-Shlomo Y, Markowe H, Shipley M and Marmot MG: Stroke risk from alcohol consumption using different control groups. Stroke 23: 1093-1098, 1992.

56. Jee SH, Park JW, Lee SY, Nam BH, Ryu HG, Kim SY, Kim YN, Lee JK, Choi SM and Yun JE: Stroke risk prediction model: A risk profile from the Korean study. Atherosclerosis 197: 318-325, 2008.

57. Singh JK, Ranjan P, Kumari A, Dahale AS, Jha R and Das R: Types, outcome and risk factors of stroke in Tribal Patients. Int J Stroke 8: 675-680, 2013.

58. Zhang J, Liu G, Arima H, Li Y, Cheng G, Shiue I, Lv L, Wang H, Zhang $\mathrm{C}$, Zhao J, et al: Incidence and risks of subarachnoid hemorrhage in China. Stroke 44: 2891-2893, 2013.

59. Lindekleiv H, Sandvei MS, Romundstad PR, Wilsgaard T, Njølstad I, Ingebrigtsen T, Vik A and Mathiesen EB: Joint effect of modifiable risk factors on the risk of aneurysmal subarachnoid hemorrhage: A cohort study. Stroke 43: 1885-1889, 2012.

60. Vlak MH, Rinkel GJ, Greebe P, Greving JP and Algra A: Lifetime risks for aneurysmal subarachnoid haemorrhage: Multivariable risk stratification. J Neurol Neurosurg Psychiatry 84: 619-623, 2013.

61. Shiue I, Arima H, Hankey GJ and Anderson CS; ACROSS Group: Modifiable lifestyle behaviours account for most cases of subarachnoid haemorrhage: A population-based case-control study in Australasia. J Neurol Sci 313: 92-94, 2012.

62. Koshy L, Easwer HV, Premkumar S, Alapatt JP, Pillai AM, Nair S, Bhattacharya RN and Banerjee M: Risk factors for aneurysmal subarachnoid hemorrhage in an Indian population. Cerebrovasc Dis 29: 268-274, 2010.

63. Inagawa T: Risk factors for aneurysmal subarachnoid hemorrhage in patients in Izumo City, Japan. J Neurosurg 102: 60-67, 2005.

64. Harmsen P, Rosengren A, Tsipogianni A and Wilhelmsen L: Risk factors for stroke in middle-aged men in Goteborg, Sweden. Stroke 21: 223-229, 1990.

65. Inagawa $\mathrm{T}$ : Risk factors for the formation and rupture of intracranial saccular aneurysms in Shimane, Japan. World Neurosurg 73: 155-164; e23, 2010.

66. Sandvei MS, Romundstad PR, Müller TB, Vatten L and Vik A: Risk factors for aneurysmal subarachnoid hemorrhage in a prospective population study: The HUNT study in Norway. Stroke 40: 1958-1962, 2009.

67. Lindekleiv H, Sandvei MS, Njølstad I, Løchen ML, Romundstad PR, Vatten L, Ingebrigtsen T, Vik $A$ and Mathiesen EB: Sex differences in risk factors for aneurysmal subarachnoid hemorrhage: A cohort study. Neurology 76: 637-643, 2011.

68. Sankai T, Iso H, Shimamoto T, Kitamura A, Naito Y, Sato S, Okamura T, Imano H, Iida M and Komachi Y: Cohort study on risk factors for subarachnoid hemorrhage among Japanese men and women. Nihon Eiseigaku Zasshi 53: 587-595, 1999 (In Japanese).

69. Leppälä JM, Paunio M, Virtamo J, Fogelholm R, Albanes D, Taylor PR and Heinonen OP: Alcohol consumption and stroke incidence in male smokers. Circulation 100: 1209-1214, 1999.

70. Thompson SG: Why sources of heterogeneity in meta-analysis should be investigated. BMJ 309: 1351-1355, 1994.

71. Feigin V, Parag V, Lawes CM, Rodgers A, Suh I, Woodward M, Jamrozik K and Ueshima H; Asia Pacific Cohort Studies Collaboration: Smoking and elevated blood pressure are the most important risk factors for subarachnoid hemorrhage in the Asia-Pacific region: An overview of 26 cohorts involving 306,620 participants. Stroke 36: 1360-1365, 2005.

72. Canhão P, Pinto AN, Ferro H and Ferro JM: Smoking and aneurysmal subarachnoid haemorrhage: A case-control study. J Cardiovasc Risk 1: 155-158, 1994.

73. Stokes GS: Hypertension and alcohol: Is ther a link? J Chronic Dis 35: 759-762, 1982

74. Moncada S and Radomski MW: The problems and the promise of prostaglandin influences in atherogenesis. Ann N Y Acad Sci 454: 121-130, 1985.

75. Laug WE: Ethyl alcohol enhances plasminogen activator secretion by endothelial cells. JAMA 250: 772-776, 1983.

76. Knekt P, Reunanen A, Aho K, Heliövaara M, Rissanen A, Aromaa A and Impivaara O: Risk factors for subarachnoid hemorrhage in a longitudinal population study. J Clin Epidemiol 44: 933-939, 1991. 
77. Bonita R: Cigarette smoking, hypertension and the risk of subarachnoid hemorrhage: A population-based case-control study. Stroke 17: 831-835, 1986.

78. Petitti DB and Wingerd J: Use of oral contraceptives, cigarette smoking, and risk of subarachnoid haemorrhage. Lancet 2: 234-235, 1978

79. Longstreth WT, Nelson LM, Koepsell TD and van Belle G: Subarachnoid hemorrhage and hormonal factors in women. A population-based case-control study. Ann Intern Med 121: 168-173, 1994.

80. Inman WH: Oral contraceptives and fatal subarachnoid haemorrhage. Br Med J 2: 1468-1470, 1979.
81. Fedirko V, Tramacere I, Bagnardi V, Rota M, Scotti L, Islami F, Negri E, Straif K, Romieu I, La Vecchia C, et al: Alcohol drinking and colorectal cancer risk: An overall and dose-response meta-analysis of published studies. Ann Oncol 22: 1958-1972, 2011.

82. Tramacere I, Negri E, Pelucchi C, Bagnardi V, Rota M, Scotti L, Islami F, Corrao G, La Vecchia C and Boffetta P: A meta-analysis on alcohol drinking and gastric cancer risk. Ann Oncol 23: 28-36, 2012. 